\title{
NOTES
}

\section{Preparation and Properties of Polyurethanes Containing Mesogenic Units}

\author{
Kazuo SugrYama*, Kohei ShIRAISHI, and Koichi Kato \\ Department of Industrial Chemistry, Faculty of Engineering, Kinki University, \\ Takaya, 1 Umenobe, Higashihiroshima 729-17, Japan
}

(Received June 18, 1992)

KEY WORDS Polyurethane / Thermotropic Liquid Crystalline Polymer / Hydrogen Bonding / X-Ray Diffraction /

Polymers in which the mesogenic moieties with flexible segments are incorporated into the backbone are known to have strongly ordered structures in the solid state and often exhibit a thermotropic liquid crystalline phase. These main-chain types of thermotropic liquid crystalline polymers (TLCPs) are mainly achieved in a variety of polyesters, polyamides, and polyethers. ${ }^{1-5}$ Not so many urethane based TLCPs have been. reported on the synthesis and their thermal and rheological properties. $^{6-11}$ In the previous paper, ${ }^{12}$ a terminal-terminal type of compound $\mathbf{1}$ was synthesized as a model for urethane based TLCPs and we understood how the hydrogen bonding interaction affects the formation of mesophase in low molecular weight liquid crystalline di[urethane]s. In the present note thermotropic liquid crystalline polyurethanes, poly\{(S)-2-hydroxypropyl 4[4-(11-hydroxy)benzylideneamino]cinnamate substituted diisocyanates $\}, 3 a-$ were prepared from the polyaddition of $(S)$-2-hydroxypropyl 4[4-(11hydroxyundecanoxy)benzylideneamino]cinnamate 2 with a series of diisocyanates.

\section{EXPERIMENTAL}

\section{Diol}

$\alpha, \omega$-Diol 2 was synthesized by the condensation of 4(11-hydroxyundecanoxy) benzaldehyde with (S)-2-hydroxypropyl 4aminocinnamate according to the method described previously ${ }^{13}$ and had the following: ${ }^{1} \mathrm{H}$ NMR $\left(\mathrm{CDCl}_{3}\right): 0.80-1.56(\mathrm{~m}, 18 \mathrm{H})$, $1.60-1.90(\mathrm{~m}, 3 \mathrm{H}), 3.28-3.56(\mathrm{t}, 3 \mathrm{H})$, $3.68-4.08(\mathrm{~m}, 4 \mathrm{H}), 6.16-6.44(\mathrm{~d}, J=16 \mathrm{~Hz}$, $1 \mathrm{H}), 6.68-7.76(\mathrm{~m}, 9 \mathrm{H}), 8.22(\mathrm{~s}, 1 \mathrm{H})$.

\section{Polyaddition}

Into a $100 \mathrm{ml}$ three-necked round bottomed flask, equipped with a magnetic stirrer, $\mathrm{N}_{2}$ inlet tube and dropping funnel, were placed a known amount of $\mathbf{2}$ in dry anisole. At the first step, $95 \%$ of the required amount of diisocyanate was slowly added to the stirred solution over a period of $2 \mathrm{~h} 155^{\circ} \mathrm{C}$. After being kept at this temperature for $2 \mathrm{~h}, 5 \%$ of residual diisocyanate was added at once and the mixture was stirred for another $4 \mathrm{~h}$. After polyaddition, the content of the reaction vessel was poured into a large amount of methanol to precipitate the solid. Polymers $\mathbf{3 a}-\mathbf{e}$ were purified by removing low molecular weight compounds by use of a Soxhlet extractor with ethanol as solvent for $20 \mathrm{~h}$.

\section{Characterization}

${ }^{1} \mathrm{H}$ NMR measurements were carried out with a $100 \mathrm{MHz}$ JEOL JNM-MH100 spectrom- 
eter. IR measurements were carried out with a JASCO IR 810 spectrometer, with a heating plate made of aluminum attached to a temperature controller. For thermal processing IR studies, $5 \%(\mathrm{w} / \mathrm{v})$ of sample were dissolved in spectrograde chloroform and poured onto $\mathrm{KBr}$ plates and the solvent removed in vacuo. The sample was sandwiched between two $\mathrm{KBr}$ plates and was used for the IR measurements. The phase transition temperature was determined by differential scanning calorimetry (DSC), using a Rigaku Thermoflex apparatus DSC-8230B. Sample quantity was $10 \mathrm{mg}$ with $10^{\circ} \mathrm{C} \mathrm{m^{-1 }}$ of heating and cooling rate. Pyrolysis was carried out with a Rigaku TG-DSC instrument standard type CN8076 E1. Polarized optical microscopy (POM) of thin samples, which were sandwiched between two glass slides (spacing, $25 \mu \mathrm{m}$ ), was performed using as Olympus microscope $\mathrm{BH}-2$ with a heating stage attached to a temperature controller. Gel permeation chromatography (GPC) measurements were carried out in THF solution with TSK-G2000HXL/TSK-G3000-
HXL/TSK-G4000HXL at room temperature, using a TOSOH HLC-8020 GPC apparatus. The degree of crystallinity was measured on powder samples by a diffraction of Macscience Co. type MXP $18 \mathrm{~V}$ using $\mathrm{Cu}-K_{\alpha}$ radiation. The scattering intensity was registered at $2^{\circ} \mathrm{min}^{-1}$ for values of $2 \theta$ ranging from $4^{\circ}$ to $40^{\circ}$. The small-angle X-ray diffraction pattern of $3 \mathbf{e}$ was taken in the solid phase, that prepared from quenching rapidly to liquid nitrogen just after annealed at $170^{\circ} \mathrm{C}$ for $30 \mathrm{~min}$. The X-ray diffraction pattern was recorded with a Rigaku RINT-1500/2203E1, E5.

\section{RESULTS AND DISCUSSION}

$\alpha, \omega$-Diol 2 used in this work exhibits the ferroelectric liquid crystalline phase: $K 57 S_{\mathrm{H}}{ }^{*}$ $112 S_{\mathrm{C}} * 132 S_{\mathrm{A}} 147 I^{13}{ }^{13}$ Diisocyanates used were 1,6-hexamethylene (HMDI), 4,4'diphenylmethane (DPMDI), 1,3-phenylene (1,3-PDI), toluene 2,4- (2,4-TDI), and toluene 2,6-diisocyanate (2,6-TDI). Table I shows the results of the polyaddition of diol to

Table I. Polyaddition a of diols 1 to diisocyanates (DI) and characterization of polyurethanes 3

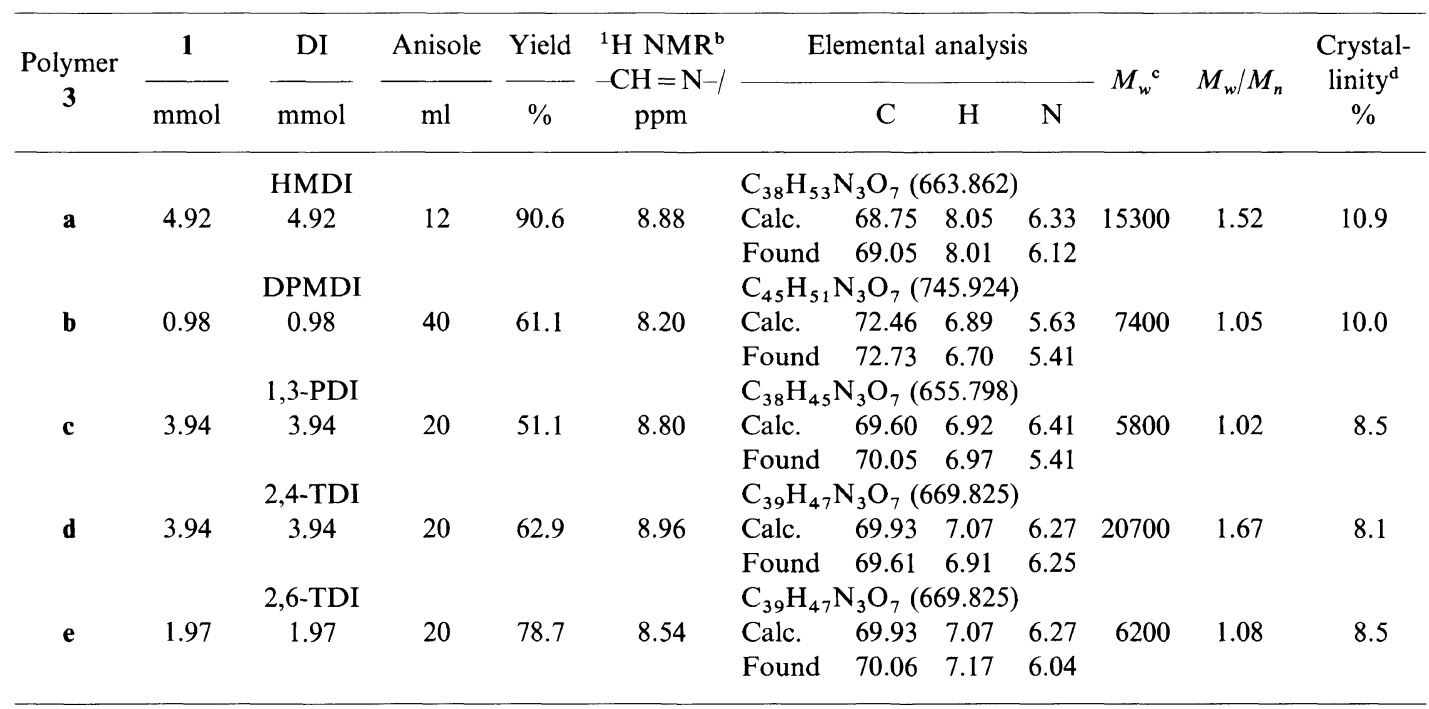

a Polyaddition was carried out in anisole at $155^{\circ} \mathrm{C}$.

b Measured in $\mathrm{CDCl}_{3}$.

c Measured by GPC with tetrahydroforan (THF) as an eluent and calibrated with standard polystyrenes.

d Determined by X-ray diffraction analysis. 

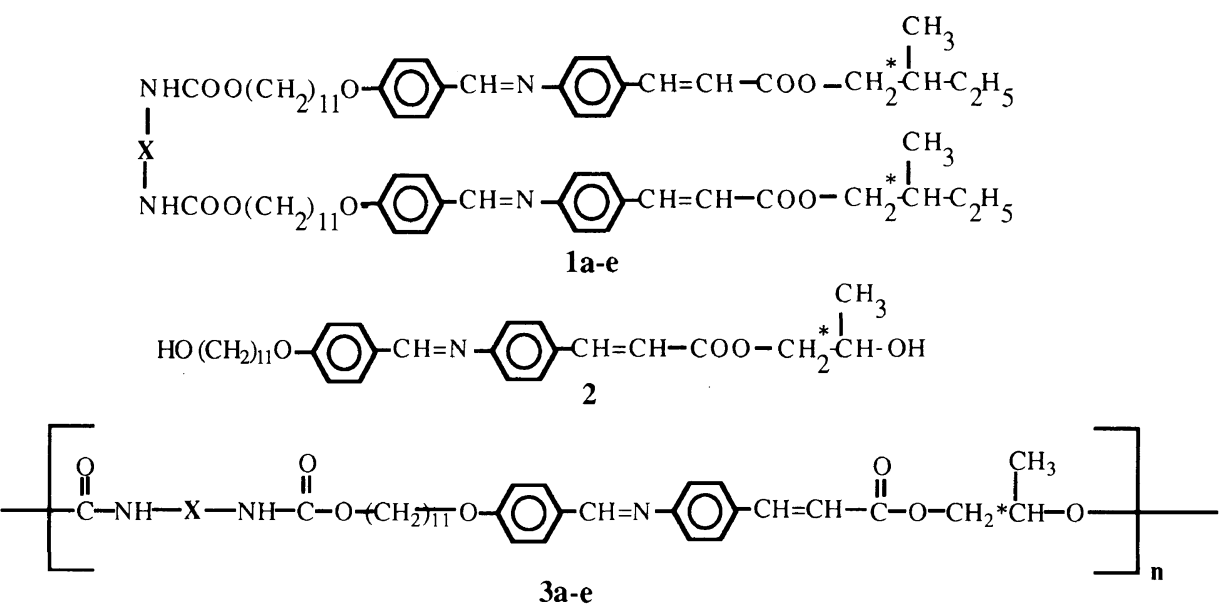

\begin{tabular}{c|ccccc}
1,3 & a & b & c & d & e \\
\hline & $-\mathrm{CH}_{26}+$ & $-\mathrm{C}$ & & &
\end{tabular}

Figure 1. Structures of twin models, diol, and polyurethanes.

diisocyanates in anisole at $155^{\circ} \mathrm{C}$ and characterization of resulting polymer. Polyurethanes 3 are soluble in chloroform with small insoluble part and the chloroform soluble fractions were discussed in this note. The structure of 3 shown in Figure 1 was identified by ${ }^{1} \mathrm{H}-\mathrm{NMR}$, IR spectroscopy and elemental analyses. IR spectra showed $\mathrm{N}-\mathrm{H}$ stretch in $3320-3340 \mathrm{~cm}^{-1}$ and $\mathrm{C}=\mathrm{O}$ stretch of urethane linkage $1960-1720 \mathrm{~cm}^{-1}$. The peaks which appeared at $8.20-8.96 \mathrm{ppm}$ in the ${ }^{1} \mathrm{H}$ NMR were attributed to the Schiff base protons. The elementral analysis data matched the theoretical values within the limits of experimental error. From GPC measurements, the molecular weight of $\mathbf{3}$ was found to be $4900-20700$. The thermal properties of the polymers were studied by DSC and POM. Figure 2 depicts the DSC traces of 3 with heating and cooling at $5^{\circ} \mathrm{C} \mathrm{min}{ }^{-1}$. The melting process of 3a, for instance, indicated by two strong endothermic peaks at $124.6^{\circ} \mathrm{C}$ (crystal-

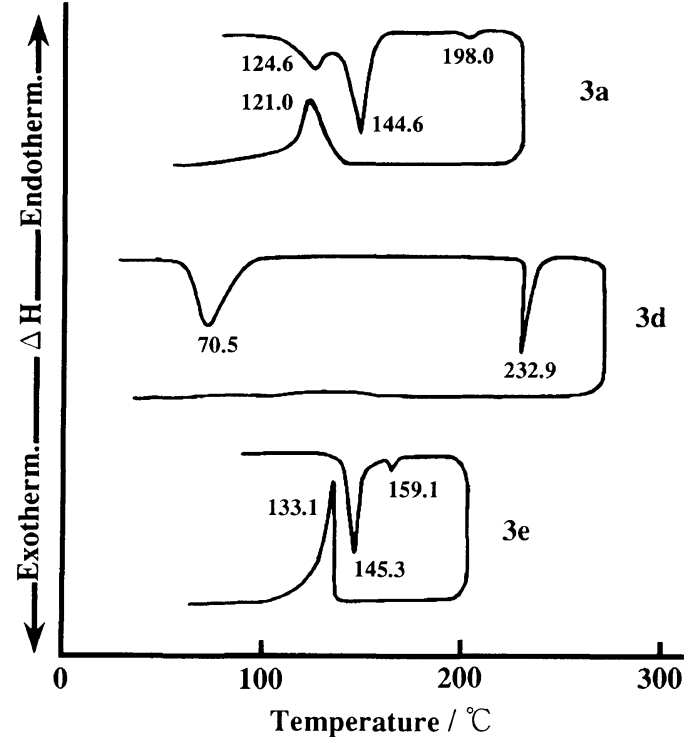

Figure 2. DSC traces of polyurethanes 3 .

line-crystalline transition) and $144.6^{\circ} \mathrm{C}$ (melting points) with a small peak at $198^{\circ} \mathrm{C}$ (isotropization transition) is followed by 
decomposition that began at $257^{\circ} \mathrm{C}$.

After annealed at the temperature below decomposition for $2 \mathrm{~h}, \mathbf{3 a}$ and $\mathbf{3 e}$ exhibit a broad exothermic peak due to crystallizing transition on cooling, while $\mathbf{3 d}$ shows no peak. DSC traces of $\mathbf{3 b}$ and $\mathbf{3 c}$ were in a similar

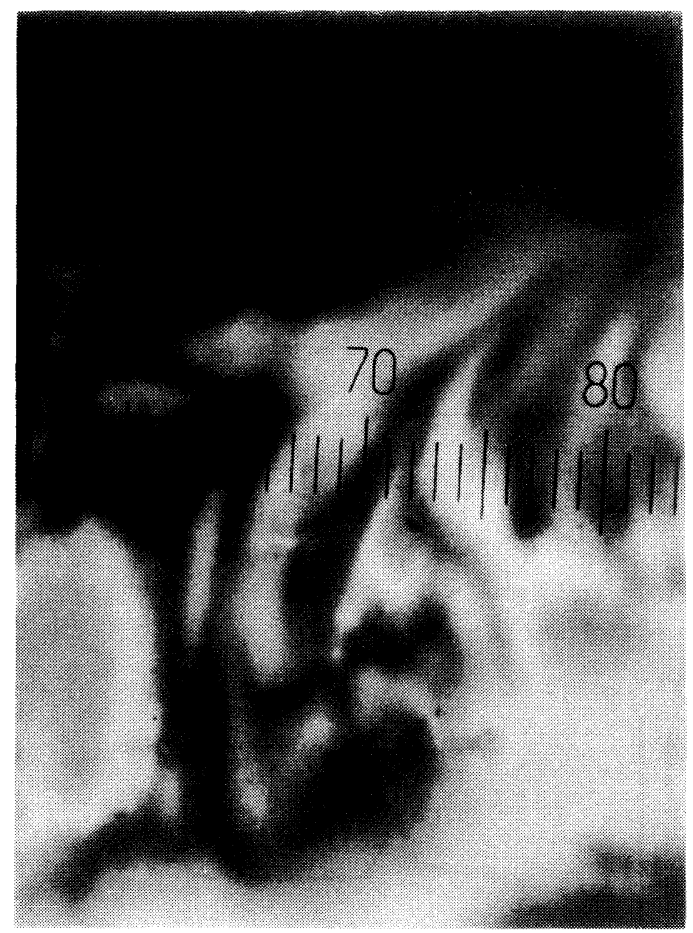

Figure 3. POM photograph of polyurethane $3 \mathrm{e}$ at $74^{\circ} \mathrm{C}$ on cooling cycle, $\times 150$. pattern as that of $\mathbf{3 d}$. POM of $3 \mathbf{e}$ reveals birefringence, which is retained even at $0^{\circ} \mathrm{C}$ as shown in Figure 3. Similar textures, frozen in the state by fairly low temperature, were observed on the other polyurethanes. The small-angle $\mathrm{X}$-ray diffraction pattern scanning for $2 \theta=0.150-10.000^{\circ}$ for the annealed sample of $3 \mathbf{e}$ at room temperature shows a broad peak at $2 \theta=3.88^{\circ}$ corresponding to an interplanar spacing of $\mathrm{d}=22.7 \AA$ as shown in Figure 4. This is assigned to the layer spacing in a smectic mesophase. ${ }^{14}$

At present, it is not known to which smectic mesophase 3 belongs. Low molecular weight compounds composed of two terminal mesogenic groups interconnected by a flexible spacer group may be taken as models for main-chain type of TLCPs which contain core units interconnected through spacer groups. ${ }^{15-18}$ The relationship between structure and property of the twin models is known to parallel that of analogous TLCPs. We have already prepared twin model $\mathbf{1 a}-\mathbf{e}$ as the prototype of urethane-based TLCPs. Table II tabulates the phase transition temperature of $\mathbf{3}$ together with that of their twin models 1 . In twin models it was found that intra- and intermolecular interation due to the hydrogen bonding play an important role in formation of mesophase. ${ }^{12}$ In twin models 1c and 1d, the rigid core unit tends to self-associate by a relatively strong in-

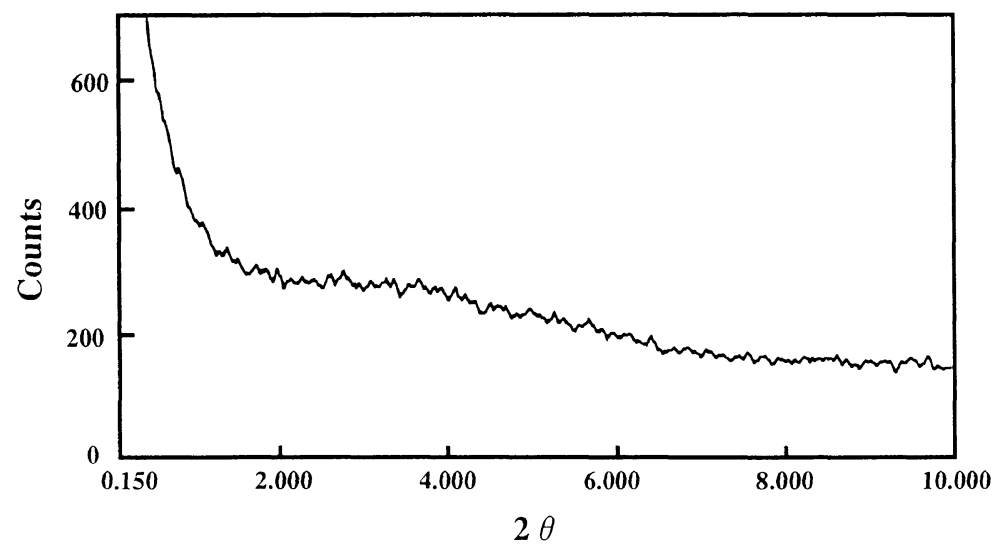

Figure 4. Small-angle X-ray diffraction scans for the annedled sample of $3 \mathbf{e}$ at room temperature. 


\section{Preparation and Properties of Polyurethanes Containing Mesogenic Units}

Table II. Phase transition temperature of twin models $\mathbf{1}$ and polyurethanes $\mathbf{3}$

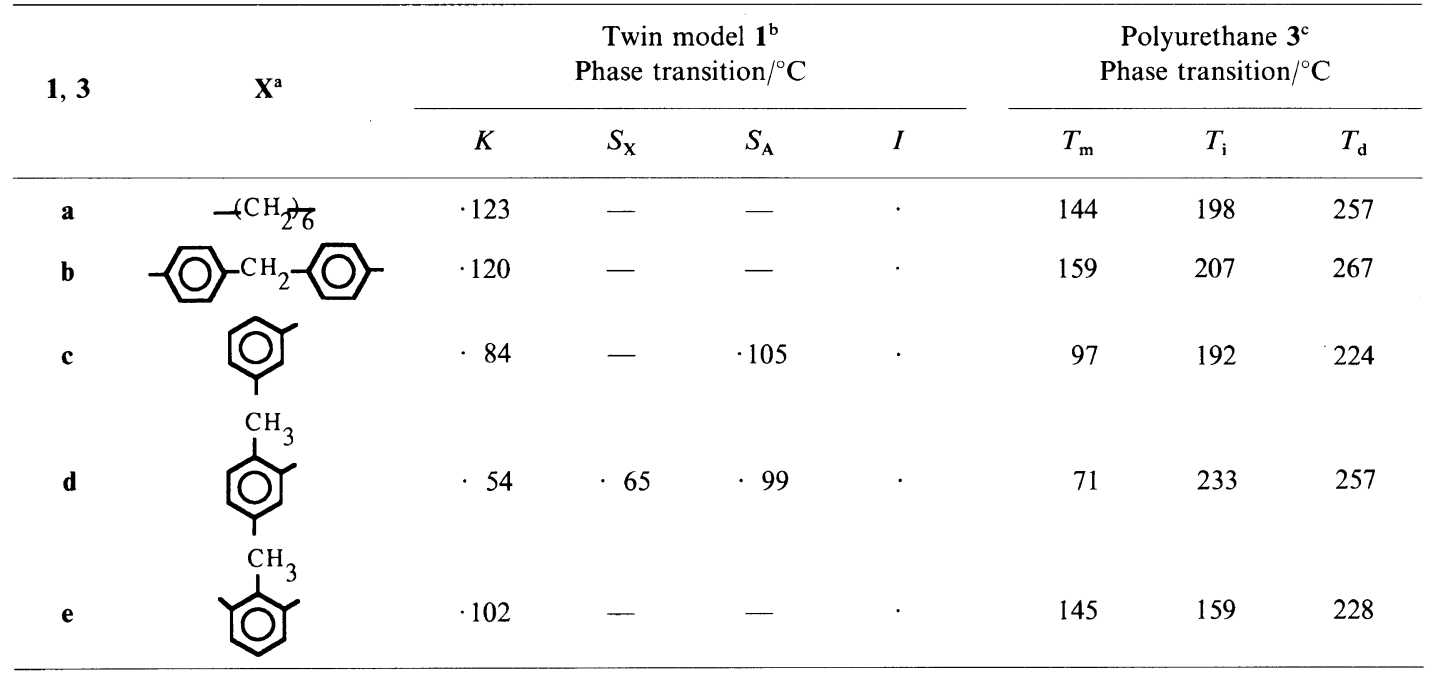

a See Figure 1.

b Reference 12 .

c $T_{\mathrm{m}}, T_{\mathrm{i}}$, and $T_{\mathrm{d}}$ represent melting points, phase transition temperature from nematic phase to isotropic melt on heating cycles, and initial decomposition temperature, respectively.
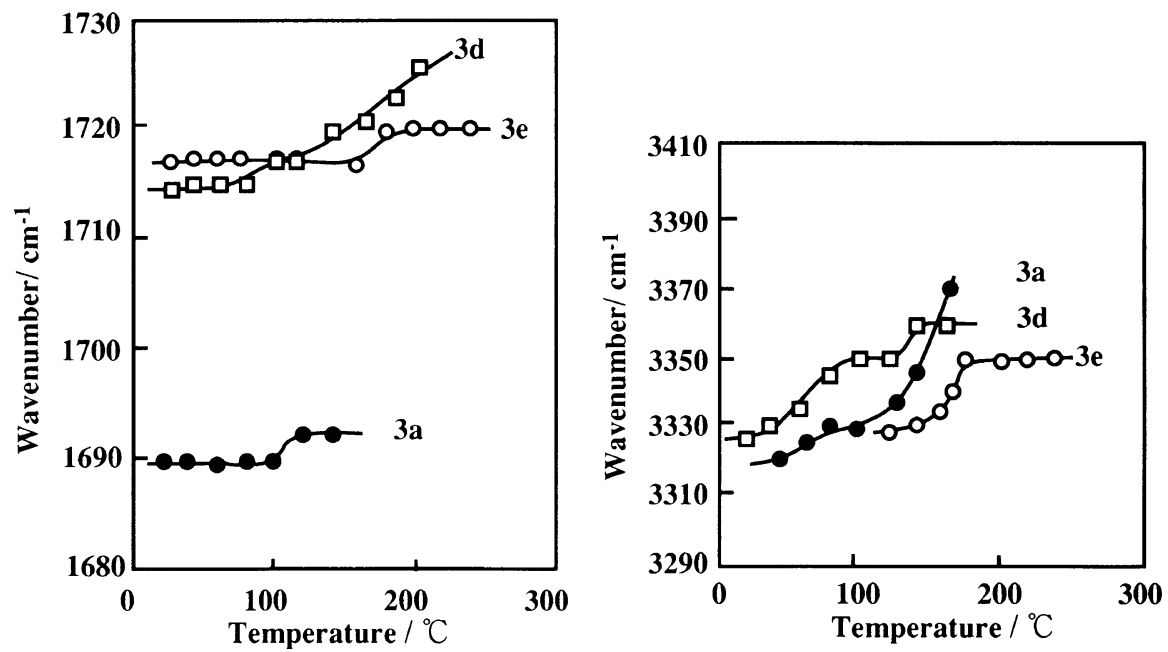

Figure 5. Temperature dependence of $\mathrm{C}=\mathrm{O}$ (left) and $\mathrm{N}-\mathrm{H}$ (right) stretching band for polyurethanes 3a, 3d, and 3e.

tramolecular hydrogen bonding and a reasonably long aliphatic chain contributes to formation of the smectic A $\left(S_{\mathrm{A}}\right)$ phase. Since the intermolecular hydrogen bonding is a dominant factor for the crystallization, other twin models 1a, 1b, and 1c exhibits the transition of crystalline-isotropic melt. In order to know how the hydrogen bonding interaction affects the formation of mesophases in polyurethanes 3 , thermal processing IR measurements were carried out. Figure 5 shows the frequency shift in IR spectra of 3a, 3d, and $\mathbf{3 e}$ 
as a function of temperature in the range of 20 to $250^{\circ} \mathrm{C}$, including the $\mathrm{N}-\mathrm{H}$ stretch and the $\mathrm{C}=\mathrm{O}$ stretch of which frequencies and relative intensities are characteristic of hydrogen bond formation. ${ }^{9}$ It was found that the stretches regarded as hydrogen bonding $\mathrm{C}=\mathrm{O}$ as well as $\mathrm{N}-\mathrm{H}$ vibration of polyurethanes gradually shift to higher frequency region with increasing temperature around their melting points. These facts suggest that the hydrogen bonding plays an important role in the development of mesophases in 3 . $^{9}$

All of 3 having structure corresponding to 1 showed a smectic phase since the mesogenic groups in the main chains are restricted to align by intermolecular interaction.

Acknowledgments. The authors thank Mr. T. Ohashi of Western Industrial Research Institute of Hiroshima for the determination of degree of crystallinity. Thanks are also due to Mr. T. Sakatani of Rigaku X-ray diffract application center for the measurements of small-angle X-ray diffraction.

\section{REFERENCES}

1. T. Uryu and T. Kato, Macromolecules, 21, 378 (1988).

2. W. H. Chen, T. C. Chang, and F. Higashi, J. Polym.
Sci., A: Polym. Chem. Ed., 26, 3269 (1988).

3. B. C. Auman and V. Percec, Polymer, 29, 938 (1988).

4. M. Marcos, F. Navarro, L. Oriol, and J. L. Serrano, Makromol. Chem., 190, 305 (1989).

5. M. Schmucki and A. D. Jenkins, Makromol. Chem., 190, 1303 (1989).

6. W. Mormann and M. Brahm, Makromol. Chem., 190, 631 (1989).

7. H. R. Kricheldorf and J. Awe, Makromol. Chem., 190, 2597 (1989).

8. M. Tanaka and T. Nakaya, J. Macromol. Sci. Chem., A26, 1655 (1989).

9. S. K. Pollack, D. Y. Shen, S. L. Hsu, Q. Wang, and H. D. Stidham, Macromolecules, 22, 551 (1989).

10. P. J. Stenhouse, E. M. Valles, S. W. Kantor, and W. J. MacKnight, Macromolecules, 22, 1467 (1989).

11. F. Papadimitrakooulos, S. W. Kantor, and W. J. MacKnight, Polym. Prepr. Am. Chem. Soc., Div. Polym. Chem., 31(1), 486 (1990).

12. K. Sugiyama, K. Kato, and K. Shiraishi, Bull. Chem. Soc. Jpn., 65, 2259 (1992).

13. K. Sugiyama, K. Kato, and K. Shiraishi, Bull. Chem. Soc. Jpn., 64, 1652 (1991).

14. G. Smyth, S. K. Pollack, W. J. MacKnight, and S. L. Hsu, Liq. Cryst., 7, 839 (1990).

15. R. B. Blumstein, M. D. Poliks, E. M. Stickles, A. Blumstein, and F. Volino, Mol. Cryst. Liq. Cryst., 129, 375 (1985).

16. H. Toriumi, H. Furuya, and A. Abe, Polym. J., 17, 895 (1985).

17. P. Esnault, D. Galland, F. Volino, and R. B. Blumstein, Mol. Cryst. Liq. Cryst. Inc. Nonlin. Opt., 157, 409 (1988).

18. G. S. Attard, S. Garnett, C. G. Hickman, C. T. Imrie, and L. Taylor, Liq. Cryst., 7, 495 (1990). 